\title{
Effect of Occlusal Reduction on Postoperative Pain in Teeth with Irreversible Pulpitis and Mild Tenderness to Percussion
}

\author{
Siddharth Ghimire, ${ }^{1}$ Punam Basnet Dixit, ${ }^{1}$ Deepak Kumar Roy, ${ }^{1}$ Shweta Dhital, ${ }^{2}$ Sirjana Dahal ${ }^{3}$ \\ ${ }^{1}$ Department of Conservative Dentistry and Endodontics, Department of Pedodontics and Preventive Dentistry, \\ ${ }^{3}$ Department of Community and Public Health Dentistry, Kathmandu Medical College, Duwakot, Bhaktapur, Nepal.
}

\begin{abstract}
Background: One of the most important aspects during endodontic treatment is to control pain during and after root canal treatment. Occlusal reduction has been widely used after root canal treatment to reduce post treatment pain and flare up. The purpose of this study was to evaluate the effect of occlusal reduction on postoperative pain in teeth with irreversible pulpitis and tenderness to percussion.
\end{abstract}

\begin{abstract}
Methods: Forty-eight patients with irreversible pulpitis and mild tenderness to percussion were allocated into two groups; occlusal tooth reduction group and no occlusal tooth reduction group. After root canal instrumentation, patients were recalled after 24 hours, $2^{\text {nd }}$ day, $3^{\text {rd }}$ day, $4^{\text {th }}$ day, $5^{\text {th }}$ day and 6 th day to record their postoperative pain on the Visual Analogue Scale. The final outcome that is mean post instrumentation pain score was measured till 6 days of post instrumentation. Data was collected and entered in Microsoft Excel sheet and analysis was done using Statistical Package for the Social Sciences software version 20 .
\end{abstract} Results: There was no significant difference in postoperative pain between the 2 groups $(\mathrm{P}>.05)$ after
root canal preparation.

Conclusions: Occlusal surface reduction did not provide any further reduction in postoperative pain for teeth with irreversible pulpitis and mild tenderness to percussion compared with no occlusal reduction.

Keywords: endodontic preparation; occlusal reduction; postoperative pain; root canal treatment.

\begin{abstract}
INTRODUCTION
Pain management in endodontics is of paramount importance for the clinicians. ${ }^{1}$ Number of studies evaluating frequency of post-operative pain following endodontic treatment have been published with highly variable reported range from $82.9 \%$ to $10.6 \%{ }^{2}$ Post instrumentation pain during endodontic procedure is detrimental occurrence for both patients and clinicians. ${ }^{3}$ Different diseases of pulp and peri-radicular pathosis are involved in causing post-operative pain in endodontic treatment. ${ }^{4,5} \mathrm{~A}$ number of different strategies have been used for managing post-operative pain after endodontic instrumentation, most commonly of which are pre-operative analgesic and steroid prescription, or administration of long acting anesthesia, and occlusal reduction. ${ }^{2}$ Occlusal adjustment decreases mechanical stimulation of sensitized nociceptors. ${ }^{6}$
\end{abstract}

Several studies have evaluated the effects of occlusal reduction on pain and discomfort after root canal treatment. ${ }^{1-3,5,7,8}$ Considering this, this study was carried out to evaluate the effect of occlusal reduction on postoperative pain in teeth with irreversible pulpitis and mild tenderness to percussion.

\section{METHODS}

A non-randomized trial was conducted in the department of Conservative Dentistry and Endodontics at Kathmandu Medical College and Teaching Hospital, Duwakot after obtaining ethical approval. All the patients were selected after meeting their inclusion and exclusion criteria for our study. The patients were divided into two groups (occlusal tooth reduction group and no occlusal tooth reduction group). A healthy patient complaining of prolonged pain to cold in either maxillary or mandibular posterior tooth with normal periapical radiographic appearance and also, the Patients having normal occlusal contact with the opposing tooth with mild tenderness to percussion and willing to continue their treatment until the placement of full-coverage restoration were included in this study.

Patients younger than 18 years were not included in our study, also the Pregnant/Lactating females, patients with systemic disorders and habit of bruxism or clenching were excluded from this study. Excluded those teeth having severe periodontal disease, associated with swelling, abutments for fixed or removable prosthesis, mobility greater than grade 1, pocket depth greater than $5 \mathrm{~mm}$ and infected root canal system. Purposive sampling was done to select the sample who have come to the department complaining of dental pain. All the patients were informed about

Correspondence: Dr. Siddharth Ghimire, Department of Conservative Dentistry and Endodontics, Kathmandu Medical College, Duwakot, Bhaktapur, Nepal. Email: drsiddharthghimire@gmail.com. Phone: +977-9851031601. Article received: 2019-08-19. Article accepted: 2020-02-12. 
Ghimire et al. Effect of Occlusal Reduction on Postoperative Pain in Teeth with Irreversible..

the objectives of the study. The patients willing to participate were included in the study only after signing an informed consent. The sample size calculation was done by using the data of similar study done by Sheikh et al. ${ }^{3}$ The estimated sample size was 48 (24 in each group). The visual analogue scale was used to measure the intensity of pain. Cohen's kappa was calculated for the reliability of the study scale for measuring inter examiner reliability $(0.84=$ almost perfect agreement $)$.

Altogether 48 patients were allocated into two groups (occlusal tooth reduction group and no occlusal tooth reduction group). The teeth were then anesthetized by using 2 cartridges of local anesthetic solution containing $2 \%$ lidocaine with 1:80,000 epinephrine (Septodent). All the endodontic treatment was performed by a single operator in two appointments. In the first appointment, access opening was done with endo assess bur (Howard Martin No. 2/ Dentsply) and determination of working length was done by apex locater (Canal Pro/ Coltene) and confirming the measurements with a periapical radiograph. For cleaning and shaping rotary instruments (Protaper Universal Files/ Dentsply) were used.

A 3\% solution of sodium hypochlorite was used as an irrigant between each instrumentation. After cleaning and shaping of canals, access cavity was sealed with a temporary restoration (CAVIT/3MESPE). For occlusal reduction group, occlusal contacts were confirmed by using articulating paper. Only the surface marked with an articulating paper was removed with a flame shaped diamond bur (Mani ISO, FO-30-F) in a high-speed hand piece with copious water spray. Occlusal reduction was not done in no occlusal reduction group. After root canal instrumentation, patients were instructed to complete a Visual Analogue Scale to score their pain at 24 hours, 2 days, 3 days, 4 days, 5 days, and 6 days. The final outcome that is mean post instrumentation pain score was measured at 6 days of post instrumentation. Before conducting this study, a pilot study was done among $10 \%$ of the sample before the start of the study. Those involved subjects in pilot study were not included in the final sample.

Data was collected and entered in SPSS and statistical analysis was done. Descriptive statistics was done using mean and median. Inferential statistics was done using chi square test for categorical data, for numerical data Mann Whitney $\mathrm{U}$ test was used.

\section{RESULTS}

Total of 48 patients ( 24 male and 24 female) with mean age of $44.04 \pm 15.858$ participated in the study. There was no significant difference in mean post instrumentation pain score after 6 days between occlusal reduction and no occlusion reduction group as presented in the following Table 1 and Table 2 .
Table 1. Comparison of mean post instrumentation pain score between groups.

\begin{tabular}{|ccc|}
\hline $\begin{array}{c}\text { Post Instrumenta- } \\
\text { tion pain }\end{array}$ & $\begin{array}{c}\text { No occlusal } \\
\text { reduction }\end{array}$ & $\begin{array}{c}\text { Occlusal reduc- } \\
\text { tion group }\end{array}$ \\
Mean $\pm \mathrm{SD}$ & $1.43 \pm 1.60$ & $1.97 \pm 1.75$ \\
\hline
\end{tabular}

\begin{tabular}{|c|c|c|c|c|c|}
\hline Time & Occlusal status & $\mathbf{N}$ & $\begin{array}{l}\text { Mean } \\
\text { Rank }\end{array}$ & $\begin{array}{c}\text { Median } \\
\text { Pain Score }\end{array}$ & $\begin{array}{c}\text { p- } \\
\text { value }\end{array}$ \\
\hline \multirow[t]{2}{*}{24 hours } & $\begin{array}{l}\text { No occlusal } \\
\text { reduction }\end{array}$ & 24 & 22.1 & 2 & 0.226 \\
\hline & $\begin{array}{l}\text { Occlusal } \\
\text { reduction }\end{array}$ & 24 & 26.5 & & \\
\hline \multirow[t]{2}{*}{2 days } & $\begin{array}{l}\text { No occlusal } \\
\text { reduction }\end{array}$ & 24 & 24.44 & 2 & 0.975 \\
\hline & $\begin{array}{l}\text { Occlusal } \\
\text { reduction }\end{array}$ & 24 & 24.56 & & \\
\hline \multirow[t]{2}{*}{3 days } & $\begin{array}{l}\text { No occlusal } \\
\text { reduction }\end{array}$ & 24 & 22.63 & 0 & 0.324 \\
\hline & $\begin{array}{l}\text { Occlusal } \\
\text { reduction }\end{array}$ & 24 & 26.38 & & \\
\hline \multirow[t]{2}{*}{4 days } & $\begin{array}{l}\text { No occlusal } \\
\text { reduction }\end{array}$ & 24 & 23.04 & 0 & 0.424 \\
\hline & $\begin{array}{l}\text { Occlusal } \\
\text { reduction }\end{array}$ & 24 & 25.96 & & \\
\hline \multirow[t]{2}{*}{5 days } & $\begin{array}{l}\text { No occlusal } \\
\text { reduction }\end{array}$ & 24 & 21.83 & 0 & 0.133 \\
\hline & $\begin{array}{l}\text { Occlusal } \\
\text { reduction }\end{array}$ & 24 & 27.17 & & \\
\hline \multirow[t]{2}{*}{6 days } & $\begin{array}{l}\text { No occlusal } \\
\text { reduction }\end{array}$ & 24 & 23.27 & 0 & 0.437 \\
\hline & $\begin{array}{l}\text { Occlusal } \\
\text { reduction }\end{array}$ & 24 & 25.73 & & \\
\hline
\end{tabular}

The mean difference between both occlusal reduction and non-occlusion reduction in relation to gender was calculated and it was found that there was no significant mean difference in pain scores (Table 3). Mean pain score was significantly

\begin{tabular}{|c|c|c|c|c|c|c|}
\hline \multicolumn{7}{|c|}{\begin{tabular}{|l|} 
Table 3. Gender variation of pain between groups \\
after 24 hours, 2 days, 3 days, 4 days, 5 days, 6 days. \\
\end{tabular}} \\
\hline \multirow{3}{*}{\begin{tabular}{|l} 
Time \\
24 \\
hours
\end{tabular}} & \multirow{3}{*}{$\begin{array}{l}\text { Occlusal } \\
\text { status } \\
\text { No occlusal } \\
\text { reduction }\end{array}$} & \multirow{3}{*}{$\begin{array}{l}\text { Gender } \\
\text { Male } \\
\text { Female }\end{array}$} & \multirow{3}{*}{$\begin{array}{l}\mathbf{N} \\
13 \\
11\end{array}$} & \multirow{2}{*}{$\begin{array}{l}\text { Mean } \\
\text { Rank } \\
11.73\end{array}$} & \multirow{3}{*}{$\begin{array}{c}\text { Median } \\
\text { Score } \\
2 \\
2\end{array}$} & \multirow{3}{*}{$\begin{array}{c}\text { p- } \\
\text { value } \\
0.549\end{array}$} \\
\hline & & & & & & \\
\hline & & & & 13.41 & & \\
\hline & Occlusal & Male & 11 & 10.64 & 2 & 0.226 \\
\hline & reduction & Female & 13 & 4.08 & 3 & \\
\hline \multirow[t]{4}{*}{2 days } & No occlusal & Male & 13 & 11.19 & 2 & 0.306 \\
\hline & reduction & Fen & 11 & 14.05 & 2 & \\
\hline & Occlusal & $\mathrm{Mal}$ & 11 & 11.23 & 1 & 0.403 \\
\hline & reduc & Fen & 13 & 13.58 & 2 & \\
\hline \multirow[t]{4}{*}{3 days } & No occlusal & Mal & 13 & 11.65 & 0 & 0.486 \\
\hline & reduction & Fer & 11 & 13.5 & 0 & \\
\hline & Occlusal & $\mathrm{Ma}$ & 11 & 11.14 & 1 & 0.365 \\
\hline & reduc & Female & 13 & 13.65 & 2 & \\
\hline \multirow[t]{4}{*}{4 days } & No occlusal & Mal & 13 & 10.38 & 0 & 0.066 \\
\hline & redu & Fen & 11 & 15 & 2 & \\
\hline & Occlusal & Male & 11 & 11.77 & 0 & 0.619 \\
\hline & redu & Female & 13 & 13.12 & 1 & \\
\hline \multirow[t]{4}{*}{5 days } & No occlusal & Male & 13 & 10.62 & 0 & 0.076 \\
\hline & reduction & Female & 11 & 14.73 & 0 & \\
\hline & Occlusal & Male & 11 & 13.18 & 1 & 0.641 \\
\hline & reduction & Female & 13 & 11.92 & 0 & \\
\hline \multirow[t]{4}{*}{6 days } & No occlusal & Male & 13 & 10.81 & 0 & 0.073 \\
\hline & reduction & Female & 11 & 14.5 & 0 & \\
\hline & Occl & Male & 11 & 13.64 & 0 & 0.387 \\
\hline & redu & Female & 13 & 11.54 & 0 & \\
\hline
\end{tabular}


higher after 5 days and 6 days of treatment among patients of age $>45$ years undergoing occlusion reduction (Table 4).

\begin{tabular}{|lllllcr|}
\hline \multicolumn{6}{|c|}{ Table 4. Age variation of pain } \\
24 hours, 2 days, 3days, & d days, 5 days and 6 days. \\
\hline Time & Occlusal & Age (in & N & Mean & Median & p- \\
status & years) & & Rank & Score & value \\
24 & No occlusal & $<45$ & 12 & 11.96 & 1 & 0.698 \\
hours & reduction & $\geq 45$ & 12 & 13.04 & 2 & \\
& Occlusal & $<45$ & 11 & 13.23 & 3 & 0.637 \\
& reduction & $\geq 45$ & 13 & 11.88 & 2 & \\
2 & No occlusal & $<45$ & 12 & 13.17 & 2 & 0.631 \\
days & reduction & $\geq 45$ & 12 & 11.83 & 2 & \\
& Occlusal & $<45$ & 11 & 11.14 & 1 & 0.371 \\
& reduction & $\geq 45$ & 13 & 13.65 & 2 & \\
3 & No occlusal & $<45$ & 12 & 12.25 & 0 & 0.85 \\
days & reduction & $\geq 45$ & 12 & 12.75 & 0.5 & \\
& Occlusal & $<45$ & 11 & 10.41 & 0 & 0.165 \\
& reduction & $\geq 45$ & 13 & 14.27 & 1 & \\
4 & No occlusal & $<45$ & 12 & 12.17 & 0 & 0.79 \\
days & reduction & $\geq 45$ & 12 & 12.83 & 0 & \\
& Occlusal & $<45$ & 11 & 10.09 & 0 & 0.099 \\
& reduction & $\geq 45$ & 13 & 14.54 & 1 & \\
5 & No occlusal & $<45$ & 12 & 12.5 & 0 & 1 \\
days & reduction & $\geq 45$ & 12 & 12.5 & 0 & \\
& Occlusal & $<45$ & 11 & 9.59 & 0 & 0.047 \\
& reduction & $\geq 45$ & 13 & 14.96 & 2 & \\
6 & No occlusal & $<45$ & 12 & 13.13 & 0 & 0.542 \\
days & reduction & $\geq 45$ & 12 & 11.88 & 0 & \\
& Occlusal & $<45$ & 11 & 9.91 & 0 & 0.049 \\
& reduction & $\geq 45$ & 13 & 14.69 & 1 & \\
\hline
\end{tabular}

\section{DISCUSSION}

The results of the present study showed that occlusal reduction had no significant effect on postoperative pain after root canal treatment of teeth with irreversible pulpitis and mild tenderness to percussion which is in accordance with other studies $^{2,5,7,9-11}$ and in contrast with the studies. ${ }^{1,3,8}$ Such differences may be due to the perception of pain is subjective and strongly dependent on the cultural, individual and economic background of the patient. ${ }^{12}$ Certain patient related factors have been recommend to significantly influence the probability of developing post-endodontic pain including age, gender, presence of occlusal contacts, presence of preoperative pain, presence of radiolucency, tooth type and presence of previous emergency endodontic treatment. ${ }^{13,14}$ Similarly certain clinician related factors have been recommended to influence the development of postoperative pain including technique used for instrumentation, type of local anesthesia, intracanal medicament used, single visit versus multiple visit endodontic treatment and pre-operative pain status. ${ }^{2}$ In this present study mean pain score was calculated among patients of age 45 years undergoing occlusion reduction and it was found that the pain scores were significantly higher after 5 days and 6 days after treatment. ${ }^{3}$

Another important factor that may influence postoperative pain is the amount of extruded apical debris after root canal treatment. ${ }^{6}$ Previous investigations on the effect of occlusal reduction used the step-back technique for root canal preparation. $^{5,8}$ In the present study, rotary instruments were used with the crown-down technique. This technique has been shown to result in significantly less apically extruded debris, ${ }^{7}$ and may be due to this result of present study varied with the previous ones. when there are more than one walls of the cavity with undermined enamel, it is considered acceptable to reduce the occlusal surface of a tooth. ${ }^{8}$

It is justifiable to continue the treatment by full coverage over the occlusal surface of the tooth after the agreement from the patient side. Different studies have recommended restoring the tooth with full coverage restoration over the posterior teeth. ${ }^{9}$ However, if the patient does not proceed with the full-coverage restoration of the tooth after root canal therapy and in case the dentist had reduced the occlusal surface to prevent from postoperative pain, the tooth may be of no use for better functioning. Therefore, clinicians and patients should be aware of the possible disadvantages associated with occlusal reduction.

\section{CONCLUSIONS}

The study findings concluded, occlusal reduction in teeth with irreversible pulpitis and mild tenderness to percussion had no significant influence on postoperative pain after root canal preparation.

\section{REFERENCES}

1. Zaman H, Ahmed SH. Effect of occlusal reduction on post instrumentation pain. PODJ. 2016; 36 (1):119-21.

2. Raza I, Ahmed A, Khalid N, Batool F. Effect of occlusal reduction on frequency of postoperative pain relief, following an endodontic instrumentation. PODJ. 2016; 36(4):650-53.

3. Sheikh H, Ahmed A, Jouhar R, Chauhdary Z. Comparison of post instrumentation pain in teeth during root canal treatment with or without occlusal reduction. PODJ. 2015; 35(4): 699-701.

4. Sathorn C, Parashos P, Messer H. The prevalence of post operative pain and flare-up in single- and multiple-visit endodontic treatment: a systematic review. Int Endod J. 2008; 41(2): 91-99.

5. Creech JL, Walton RE, Kaltenbach R., "Effect of occlusal relief on endodontic pain", J Am Dent Assoc. 1984; 109 (1):64-7.

6. Wolcott J, Rossman LE, Hasselgren G. Management of endodontic emergencies. In: Hargreaves KM, Cohen S, eds. Pathways of the Pulp, 10th ed. St Louis, MO: Mosby Elsevier; 2011: 30-42. 
Ghimire et al. Effect of Occlusal Reduction on Postoperative Pain in Teeth with Irreversible..

7. Parirokh M, Rekabi AR, Ashouri R, Nakhaee N. Effect of Occlusal Reduction on Postoperative Pain in Teeth with Irreversible Pulpitis and Mild Tenderness to Percussion. J Endod. 2013 Jan; 39(1): 1-5.

8. Rosenberg PA, Babick PJ, Schertzer L, Leung A. The effect of occlusal reduction on pain after endodontic instrumentation. J Endod. 1998 Jul; 24(7): 492-96.

9. Asghar S, Fatima F, Ali A. Occlusal reduction reduces postoperative pain after endodontic instrumentation. Pak Oral Dental J 2014; 34(3): $539-42$.

10. Zeidan BM. Evaluation the effect of occlusal reduction on postoperative pain in teeth with irreversible pulpitis and mild tenderness to percussion. Journal of Al Rafidain University College 2016/38.

11. Arslan H, Seckin F, Kurklu D, Karatas E,
Yanikoglu N, Capar ID. The effect of various occlusal reduction levels on postoperative pain in teeth with symptomatic apical periodontitis using computerized analysis: a prospective, randomized, double-blind study. Clin Oral Investig. 2017 Apr;21(3):857-863

12. Dorner TE, Muckenhuber J. Stronegger WJ, Rasky E, Gustorff B, Freidl W. The impact of socio-economic status of pain and the perception of disability due to pain. European Journal of Pain. 2011, 15,103-9

13. Arias A, de la Macorra JC, Hidalgo JJ, Azabal M. Predictive models of pain following root canal treatment: a prospective clinical study. Int Endod J. 2013; 46 (8), 784-793.

14. Memon MA, Memon MR, Ali F. Assessment of the interappointment pain by using two different intracanal medicaments. PODJ. 2013; 33(1): 145-150.

Citation: Ghimire S, Dixit PB, Roy DK, Dhital S, Dahal S. Effect of Occlusal Reduction on Postoperative Pain in Teeth with Irreversible Pulpitis and Mild Tenderness to Percussion. JCMS Nepal. 2020; 16(1):17-20. 